Darius Žeruolis*

Institute of International Relations and Political Science of the University of Vilnius

Giedrius Jucevičius"

Kaunas University of Technology

\title{
The Content of the Strategic Dimension of Lithuania's Economic Policy in a Comparative Perspective
}

\begin{abstract}
This article analyses the concept, content, and historical experiences of strategic planning in modern economic policy-making. It does so also through the analysis of the case of Lithuania, which has recently undergone transformation from the centrally planned to the fully functioning market economy and now faces new challenges as a member-to-be of the European Union. The central thesis of this article is that the long-term competitiveness of the Lithuanian economy will be determined by its "micro" or enterprise-level policies, which, according to the effectiveness of implementation, will much depend on the capacity of Lithuanian institutions to manage the dilemmas of EU industrial policy.
\end{abstract}

\section{Introduction}

This article seeks to explore the concept of strategic planning in modern economic policy-making, which in the broadest sense can be understood as an intentional state intervention into economy. It also analyses the content of the strategic dimension in the Lithuanian economic policy-making during the recent transformation from the centrally planned to the fully functioning market economy. The article begins with a methodological distinction between the concepts of 'strategy' and 'policy'. This distinction is then continued by a historical overview of the role of the state in economic policy-making, namely, through a comparative analysis of several types of state intervention, such as import substitution (Latin America), developmental (East and South East Asia), and the EU (combining neoliberal and welfare policies). It then analyses EU industrial policy as the management of dilemmas, or, in other words, reconciliation of seemingly mutually exclusive economic policy goals on both community and national levels. The article continues with the statement that a "correct' (i.e. EU-compatible, defined through the "micro" or enterprise-level) understanding of competitiveness has been already established among Lithuania's institu-

"Darius Žeruolis - Director of the Integration Strategy Department of the European Committee under the Government of the Republic of Lithuania, Lecturer of the Institute of International Relations and Political Science of the University of Vilnius. Address: Gedimino pr. 56, LT-2685, Vilnius, Lithuania, tel. +370-5-2661702, e-mail: darius@euro.lt

"Giedrius Jucevičius - Ph. D. candidate of the Bussiness Strategy Institute of the Kaunas University of Technology, Address: Donelaičio 20, LT-3000 Kaunas, Lithuania, tel. 8-682-14664, e-mail: giedrius2000@hotmail.com. 
tions and market players. However, by using the Irish example the article concludes that this understanding alone will not suffice to achieve a long-term competitiveness of the Lithuanian economy. The prospects of Lithuania's capacity to withstand the competitive pressure in the European Union to a large extent will depend on the capacity to manage the dilemmas of industrial and economic policies.

\section{Economic strategy or economic policy?}

The strategic dimension is increasingly penetrating the drafting vocabulary of Lithuanian institutions. During the period of 2000-2002, the Parliament (Seimas) adopted more legal acts implying the 'strategic' dimension than during the entire first decade of independence. Evidently, the concept of strategic planning is quite new for the country's public administration and therefore it should come as no surprise that the variety of adopted 'strategic' documents almost matches the variety of the interpretations of the concept. The eve of Lithuania's 'strategic' membership in the EU and NATO calls for the evaluation of the strategic approach and its manifestations in the country's economic policy as well as the analysis of its substance and its shaping factors.

The difficulty in the interpretation of the content of strategic planning often results from the fuzzy distinction line between the concepts of 'policy' and 'strategy'. Webster's Collegiate Dictionary ${ }^{l}$ provides several definitions for 'policy'. The first one defines policy as "a definite course or method of action selected from among alternatives and in light of given conditions to guide and determine present and future decisions". In another version, policy is "a high-level overall plan embracing the general goals and acceptable procedures especially of a governmental body". ${ }^{2}$

The same dictionary also defines strategy as "the science and art of employing the political, economic, psychological, and military forces of a nation or group of nations to afford the maximum support to adopted policies in peace or war". Yet another, a more succinct definition presents strategy to be "an art of drawing plans for achieving certain goals". Notice that the latter is rather closely linked with the definitions of policy. To summarise, strategy can be best defined as a coordinated set of actions for the attainment of a certain objective. The rationale of strategic planning is to empower a social actor to make the best use of available resources and opportunities by avoiding external threats. Strategy provides the direction and a long-term perspective for the operational activities (Keller, 1990) .

Based upon these definitions, both strategy and policy concepts can be associated with logical structures underlying the decision making process of a state or organisation. In the case of Lithuanian public administration, it is not surprising at all that the distinction between the two concepts in many cases has been rather vague, because recently a number of new policy areas (e.g. small and medium enterprises, industrial competitiveness, regional/structural policies, etc.) have emerged anew or were redesigned completely. Also, as Lithuania only recently has undergone the transition from the principles of central to strategic planning, hence the proliferation of strategies and notions of what they imply.

\footnotetext{
${ }^{1}$ Webster's Collegiate Dictionary, http://www.m-w.com/cgi-bin/dictionary, accessed on 15 October 2002.

${ }^{2}$ Ibidem.

${ }^{3}$ Keller B. S., (1990) "Using Strategic Planning in Economic Development", Economic Development Review, 8 (2), Spring, pp. 20-25.
} 
However, it must be emphasised that the underlying conceptual differences between the two concepts should not be overlooked because of apparently fuzzy conceptual boundaries. The central definition of 'strategy' clearly emphasises the ability to make use of the available resources for a purposeful implementation of the adopted policies. Thus, if policy is more concerned with procedural aspects, strategy deals with the direction and principles of actions. Strategy implies a systemic approach, which is not necessarily present in the definition of policy. To conclude, if policy can be defined as "a course of actions", then strategy would mean the "co-ordinated entirety of action courses".

Logically, economic strategy could be defined as the co-ordinated entirety of economic policies. National economic policy is in popular terms defined as "the government policy oriented to ensure the economic growth and collection of taxes" 4 and is carried out through a variety of macro- and micro-level policies. The macroeconomic level mainly encompasses fiscal and monetary policies, while microeconomic is represented by industrial, small and medium enterprises, competition, innovation and technology, trade and investment, infrastructure (telecommunication, energy and transport) policies.

It thus becomes clear that the analysis of the country's economic strategy should touch upon a very wide range of policies. Therefore, even a systemic evaluation of the country's economic strategy demands certain concentration on the focal points. In this context, there is an intentional distinction between macroeconomic and microeconomic policies. Macroeconomic policies are mainly associated with the traditional economic functions of stabilisation and distribution, while microeconomic policies have more direct impact on the economic growth. Since the ultimate goal of national economic strategy is a sustained growth of economic competitiveness and, consequently, improvement of the standard of living, it is rational to focus mainly on 'micro' level policies and strategies.

It is widely agreed that structural competitiveness of national economy is determined by micro-level factors, such as investment into research and development, promotion of entrepreneurship, or even by the creation of new forms of cooperation, and not so much if at all by macroeconomic indicators (e.g. exchange or interest rates). This is not to imply or justify a potential disregard for macroeconomic policies. However, as Hughes and Hare $(1991)^{5}$ tend to observe, the impact of macroeconomic policies on the economic restructuring and long-term competitiveness of enterprises remains rather limited. In this context, it seems appropriate to remember the notorious Stability (and 'Growth') Pact and the EU member states' delicate search for a balance between the macroeconomic stability guarantees and preconditions for the 'microeconomic' dynamism.

These 'micro-level' policies are often covered by the general term of 'industrial policy', or in a more recent paradigm, 'industrial competitiveness policy'. Despite some instrumental differences, both terms stand for the "government efforts to influence the industrial structure in order to promote productivity and economic

\footnotetext{
${ }^{4}$ www.dictionary.com, source: WordNetR 1.6., 1997 Princeton University, accessed on 15 January 2002

${ }^{5}$ Hughes, G., and Hare, P. (1991) "Industrial Policy and Restructuring in Eastern Europe”, Oxford Review of Economic Policy, 8, pp. 82-104.
} 
growth" (Bora et al, 2000) ${ }^{6}$. In this case, the term 'industry' covers not only manufacturing (as often misperceived in transitional economies), but also other productive sectors of economy, such as business services.

The article will continue with a search for manifestations of the strategic approach and its influence on Lithuania's economic transformation process. The role of the industrial competitiveness policy in the wider context of economic transformation will be explored too. Finally, the impact of European integration processes and the Single market framework on the substance of national economic strategy in terms of new challenges will be analysed. However, the analysis of dominant approaches to industrial policies would be useful also from the historical perspective before this endeavour.

\section{From central to strategic planning}

The strategic planning dimension in public administration, especially in its economic policy, takes a variety of forms even in the states with a consolidated market economy. The importance of such strategies is determined by the dominating economic ideologies, traditional national business and governance systems in a given country.

In the (neo)liberal Western economies, such as the United States or Britain, the raison d'etre of the industrial policy lies in the correction of market failures or the creation of (static) competitive advantages in the international trade. It is recognised that, in certain cases, the market effect may be suboptimal and needs to be compensated by the 'corrective' action from the state. For example, small and medium enterprises (SME's), responsible for a substantial share of employment and flexibility of economic structures, find themselves disadvantaged in respect to large companies as regards, for example, market information or credit opportunities. This usually provides a sufficient justification for specific government programmes to support the informational-financial infrastructure for SME's. The government also co-finances the innovation processes in enterprises given their overall importance for a sustained economic growth, whereas, however, markets alone may not guarantee the economic gains on the micro-level. Despite the prevailing liberal line of thinking, the US government had a substantial impact on economic competitiveness through federal financing of 'national security' R\&D projects (Etzkowitz, Brisolla, 19997). Nevertheless, the substance of industrial policy is dominated by horizontal measures without priority sectors or enterprises and is combined with the balanced macroeconomic policy. In this line of thinking, spontaneous interactions of market forces and free competition rather than structured government policy remain the driving force behind competitiveness.

If approaches to industrial policy were located on a continuum, the (South) East Asian economies would represent the other extreme. They emphasise the proactive role of state institutions in promoting a sustained productivity growth. This role

\footnotetext{
${ }^{6}$ Bora, B., Lloyd, P. J., and Pangestu, M. (2000) "Industrial Policy and the WTO", World Economy, 23(April 2000), pp. 543-560.

${ }^{7}$ Etzkowitz H., Brisolla S. N. (1999) "Failure and Success: the Fate of Industrial Policy in Latin America and South East Asia", Research Policy, 28, pp. 337-350.
} 
is reflected by the implementation of long-term development plans, in-depth industrial analyses and targeting the 'priority' sectors, systemic adaptation of imported models and technologies, and a close government-enterprise interaction. Japan or 'Asian tigers' have an established protectionist tradition in sheltering infant industries from the international competition. In this ideological line, an active state policy rather than free market mechanisms underlies the structural changes in industry (Kobayashi, $1989^{8}$ ). For example, an unprecedented growth, annually averaging to 9 per cent, achieved by the South East Asian economies in 1965-1984, is to a large extent attributed to their successful assessment of local and international environment and the implementation of accordingly formulated export-oriented industrial strategies. On the other hand, the protectionist policies of Latin American states (e.g. Brazil or Argentina), focusing on the promotion of import substitutes and self-sufficiency of the local market did not 'raise' internationally competitive firms and sustained the productivity growth (Etzkowitz, Brisolla, 1999). Another systematic difference between the two cases was that in the case of the 'Asian tigers', the protectionist element was associated with the promotion of all-level national educational establishments, diminished social inequalities and increased funding for research and development.

\section{Historical perspectives - import substitution and developmental states}

Literature of political economy describes two main historical types of stateeconomy relations, namely, import substitution and developmental states. These types usefully describe economic policy-making in historic and regional terms. So while import substitution is characteristic of Latin America of the 1950's -1980's, a developmental state best describes the rapid economic growth in East and South East Asian 'tigers' during roughly the same period.

Of course, different historical circumstances make it difficult to draw very detailed policy recipes from the experience of economic modernisation of other countries. Still, a historical excursion can be useful in order to grasp the options available, especially keeping in mind occasional references by Lithuanian policymakers to these regions. While statements about underused industrial capacities inherited from the Soviet Union were abundant at the early stages of the transition, it can be safely concluded that probably because of a high dependency on international financial organisations, in the Lithuanian case, import substitution of the Latin American scale would have been least likely.

Import substitution as a deliberate strategy of economic development was designed in Latin America in the 1950's. It was based on the conclusion that the main obstacle for the rapid economic development of Latin America was its high dependency on exports of raw materials and imports of industrial and technological goods. It started out as a spontaneous response to the great depression before World War II and was consolidated in the 1960's - 1970's with a shift towards the production of

\footnotetext{
${ }^{8}$ See: Pitelis, Ch. (1994) "Industrial Strategy: For Britain, in Europe and the World", Journal of Economic Studies 21 (5), pp. 3-92.
} 
consumer durables and development of heavy industry. From the mid-1970's, some of Latin American countries (such as, for example, Mexico and Venezuela) began to complement import substitution with exports of oil, and in the 1990's Latin America (with some populist exceptions) became a true student of the Washington consensus.

The initial (primary) stage of import substitution for consumer non-durables was characteristic of all developmental states, including the East Asian 'tigers'. However, further stages of import substitution (culminating, as a rule, in the development of heavy industry) were observed only in Latin America and mainly because long-term interests of their governments (states) coincided with short-term interests of various social groups. A shift to the export-oriented economic policy in Latin America was impeded by well-entrenched distribution coalitions that led to a political stalemate. Various distribution coalitions (agrarian interest groups in control of main exports, anti-oligarchic coalitions composed of lower social classes and nonexport agrarians, state elite, namely, military officers and state bureaucrats as well as local and international industrialists) were spared by the absence of World War II. They were further consolidated by the successful primary import substitution policy. None of these groups alone were strong enough to design and implement other economic programme than import substitution. This situation is typical in the absence of state autonomy.

The secondary import substitution policy is defined as capital and technology intensive industrialisation (e.g. automobiles, petrochemicals, steel, heavy machinery). This policy suffers from the following monetary and fiscal deficiencies. It overvalues local currency, thus encouraging sales of production in domestic markets. It relies on heavy foreign borrowing, and is based on 'a cheap money policy' - low interest rates, which aim to encourage investment into industry. In fact, it frequently results in excessive investment into the capital-intensive sector with excess capacity which is often wasted - the number of jobs created is smaller than otherwise might have been. Since, as it has been mentioned, capital and technology intensive strategies are at the very heart of this policy, heavy industry becomes a strategic sector. It draws disproportionately on national savings to create output for a relatively long period and usually at a very high cost. If high costs are subsidised, heavy industry becomes a permanent burden on the budget. If it is not, costs are off-loaded on the downstream manufacturing thus inflating their production costs. As there is no competition from imports, heavy industry becomes technically obsolete. As a rule, import substitution strategy also underinvests in agriculture. Agricultural goods are relatively underpriced in comparison to industrial goods - this causes outmigration from rural areas. Crucially, the secondary import substitution industrialisation inflicts a strong skew in consumption patterns:

Creating an industrial structure solely on the basis of the domestic market entailed producing an industrial output, which exactly matched the existing distribution of income, which usually meant a bundle of retail goods strongly skewed towards upper-income consumption. Thus, as with basic foodstuffs in agriculture, mass consumption was sacrificed to the redistribution of profits towards industry. ${ }^{9}$

\footnotetext{
${ }^{9}$ Harris, N. (1990) The End of the Third World, Penguin Books, p. 128.
} 
East and South East Asian economic policies after World War II can be best summarised as a guided development. A developmental state (in most literature synonymous to an autonomous state) usually possesses enough autonomy vis-a-vis society in pursuit of developmental aims and is capable of implementing developmental strategy. In other words, such state has enough powers of social control and free design.

There are four main indicators of state autonomy. First, historical superiority of the state over the society combined with a successful social engineering, for example, successful structural reforms at some stage - especially the land reform. Intentionally or not, they create an egalitarian social structure, which is necessary for a successful development because they destroy the existing distribution coalitions. Wellentrenched coalitions always are interested in maintaining the current social and economic order. ${ }^{10}$ The egalitarian social structure is a necessary condition for development. Economic policy is always tailored to the existing consumption patterns in a given society: when a country starts off with a high inequality, there is a big danger that production will be 'upwardly skewed'. Countries sometimes do not develop not because they do not have resources, but because they misallocate them.

Second, developmental states are capable of coming up with a coherent developmental plan. Furthermore, they are flexible enough to adjust policy measures to the changing world markets (anything that benefits the development is acceptable). They possess sufficiently insulated bureaucracy to design and implement economic policies (although, retrospectively it can be said that autonomous states exhibit a blend of bureaucratic steering and corporatism). Third, developmental states are capable of extracting capital. After all, no development is possible without a back-up of sufficient resources to sustain growth. It is absolutely vital that a state has resources when developmental policies are changed, for example, from the import substitution industrialisation to export-oriented policies. Fourth, the development is guided in the sense that the state not only extracts resources, but it also lays down principles for capital allocation through investment strategies.

There were many attempts to juxtapose import substitution to developmental states. However, these two types are not completely opposites ${ }^{11}$. On the one hand, historically developmental states also practised import substitution. To be true, this happened only in the early stages of industrialisation through consumer non-durables. On the other hand, while East Asia avoided state capture of the Latin American depth, eventually the relationship between businesses and bureaucracy in East Asia can hardly be described as very ethical. A critical analysis of the "tigers" growth shows that it most probably was "growth without development". In other words, an impressive economic growth was achieved at the expense of stagnating political and democratic institutions and therefore in the long run such growth is not sustainable ${ }^{12}$. Some analysts even question the economic prospects for East Asia by stating that their success was temporary and based on an extensive development that did not

\footnotetext{
${ }^{10}$ These issues are analysed in great detail in Olson, M. (1982) The Rise and Decline of Nations, New Haven: Yale University Press.

${ }^{11}$ See: Jenkins, Rh. (1991) "Learning from the Gang: are there Lessons for Latin America from East Asia?", Bulletin of Latin American Research, 10(1), pp. 37-54.

${ }^{12}$ See, for example, Bieliūnaitè, Ž. (2001) Augimas be pletros Pietryčiu Azijos šalyse (Growth without Development in South East Asia), MA thesis (in Lithuanian), Institute of International Relations and Political Science, University of Vilnius.
} 
match the productivity growth. Therefore, in the long run these states cannot be considered as serious rivals for Western Europe and North America ${ }^{13}$.

So the empirical observations of the past several decades hardly indicate a superior, not to mention the single best approach to industrial development. Both liberal and interventionist economic policies have shown different rates of growth in different stages of development. It is even possible to observe some trends of convergence in policy approaches. General external phenomena, such as globalisation and information society, bring about visible changes to national economic systems. The traditional liberal-interventionist classification becomes increasingly complex and overlapping, if not obscure.

On the one hand, there is a set of factors that point towards the growth of neoliberal ideas and market-oriented policies. From the legal point of view, global and regional liberalisation agreements make it increasingly difficult for the national governments to pursue interventionist policies of the 1970's or 1980's. Practical effectiveness of the protectionist approach in the time of fast technological changes and importance of global knowledge networks is also subject to serious doubt.

On the other hand, even the classical 'liberal' Western economies take into consideration the achievements of South East Asian states, stemming from a more co-operational-collectivist, long-term focused and integral approach to the economic development. A rather recent concern of their governments for 'industrial strategy' owes a lot to the East Asian success stories.

The need for the industrial strategy is now rarely being questioned in principle. Instead, another question is being raised - what should be an appropriate mix of industrial policies in a given local and international situation? Thus, despite the persisting differences in national economic systems, a growing consensus on the need for the strategic approach in managing economic development processes can be observed.

\section{European industrial policies: national and community levels}

Industrial policy in Europe must be discussed taking into consideration both national and community levels, as they both provide policy examples or guidelines for Lithuania and other EU candidate countries. There is a wide range of notions and definitions of industrial policy across the current EU member states. France and most of South European states have an established dirigiste economic policy tradition with state support to 'strategic' enterprises and economic/technological projects of 'strategic importance'. On the other end of the scale are Great Britain, Ireland, the Netherlands and Scandinavian countries with a more traditional emphasis on consumer markets as drivers of national economic competitiveness. Such classification may seem to be somewhat obsolete taking into consideration social aspects of business systems, especially those of 'liberal' Scandinavian welfare economies. However, one of the most complex and problematic for a linear generalisation is the German approach to industrial policy. According to Scott $(1992)^{14}$, Germany takes a neutral

\footnotetext{
${ }^{13}$ See, for example, Krugman, P., "The Myths of East Asian Miracle", http://web.mit.edu/krugman/ www/myth.html, accessed in September 1998. This article was also published in Foreign Affairs.

${ }^{14}$ Quated in Pitelis, Ch. (1994) "Industrial Strategy: For Britain, in Europe and the World", Journal of Economic Studies 21 (5), pp. 3-92.
} 
stance in the earlier-mentioned dichotomy of the consumer-producer orientation. By the aspect of close co-operation between state institutions and industrial structures as well as by its capacity to promote the establishment of agglomerates of hi-tech firms, German industrial policy would come closer to the Japanese case. On the other hand, the German government never, at least during the last 50 years, undertook interventionist actions of the South East Asian scale; moreover, until the late 1960's, German industrial policy could hardly be distinguished as a separate variable of economic policy.

\section{Implications of the Community industrial policy for the national competitiveness}

Given such a variety of national industrial policies, it is not surprising that the EU industrial policy has always had a complex and often vague content. It is possible to state that the European integration as such owes a lot to the sectorial industrial policy measures introduced at the time of "strategic" coal and steel industries. Of course, the emergence of such policy in the post-war Europe was preconditioned primarily by the calculus of high politics rather than economic policy. To some extent, it is still possible to observe the rudiments of the post-war industrial policy, if not in the substance of today's EU policy, then at least in the aspects of legal classification. For example, the 'Industrial policy' chapter of EU screening lists for candidate countries includes only 13 directives, all of them a part of the European Coal and Steel Community legislation, which already expired in 2002. Naturally, one must ask whether all this means an end to the EU industrial policy.

Hardly so. It only shows that in a complex entity such as the European Union and in the time of a decreasing scope of the government economic intervention, industrial policy may no longer be perceived in its narrow traditional sense as direct state efforts to form the industrial structure through vertical measures. The EU competence encompasses a wide range of policies with a significant impact on enterprise competitiveness, but without being a part of the formal 'industrial' acquis. There is also an unequal distribution of competence between community-national and subnational levels across different policy areas (see: Table). 
EU industrial competitiveness policies, their instruments and levels of competence (adopted from Lawton, 1999) ${ }^{15}$

\begin{tabular}{|c|c|c|}
\hline Policy instrument & Level of competence & Examples of policy areas \\
\hline R\&D initiatives & $\mathrm{EU}+$ national & Framework programmes, Eureka \\
\hline Competition rules & EU+national & $\begin{array}{l}\text { Antitrust, monitor state aid and mergers and } \\
\text { acquisitions }\end{array}$ \\
\hline Trade policy & EU & $\begin{array}{l}\text { Antidumping, rules of origin, local content, } \\
\text { voluntary export constraints }\end{array}$ \\
\hline Export-promotion & national & Credit guarantees for export-led firms \\
\hline Tax incentives & national & $\begin{array}{l}\text { Tax relief or exemptions for start-ups or for } \\
\text { companies undertaking restructuring }\end{array}$ \\
\hline Procurement & national & Public sector contracts to firms \\
\hline $\begin{array}{ll}\text { Transport } & \text { and } \\
\text { infrastructure } & \end{array}$ & EU & $\begin{array}{l}\text { Trans-European road, air, rail, sea, transport and } \\
\text { communications networks }\end{array}$ \\
\hline Training and education & EU+national & $\begin{array}{l}\text { Promotion of human capital, employment } \\
\text { initiatives }\end{array}$ \\
\hline $\begin{array}{ll}\text { Inward } & \text { investment } \\
\text { incentives } & \end{array}$ & $\begin{array}{l}\text { National+sub- } \\
\text { national }\end{array}$ & $\begin{array}{l}\text { Provision of low-cost green field sites; period of } \\
\text { tax relief or immunity }\end{array}$ \\
\hline Enterprise policy & EU & $\begin{array}{l}\text { Integrated programmes for SME's, creation of the } \\
\text { European Investment Fund }\end{array}$ \\
\hline
\end{tabular}

Article 157 of the Maastricht Treaty sets the legal ground for the EU industrial policy by stating that "the Community and the Member States shall ensure that the conditions necessary for the competitiveness of the Community's industry exist". The article sets four main policy directions: (1) speeding up the adjustment of industry to structural changes, (2) encouraging an environment favourable for undertakings, especially SME's, (3) encouraging an environment favourable for the co-operation between undertakings, (4) fostering a better exploitation of the industrial potential of policies of innovation, research and technological development. Decisions in the Council require a unanimous support. The article does not provide the Community with legal powers to adopt measures that infringe the competition rules, thus preserving the superiority of the EC competition policy. The same article envisages that the EU industrial policy may be carried out through "other policies and activities it pursues under other provisions of the Treaty", as indicated in Table 1.

According to Darmer and Kuyper $(2000)^{16}$, in relative terms, the EU is composed of ten interventionist and five liberal member states. However, given the prevailing interventionist attitudes, it may appear paradoxical that the EU industrial policy has remained largely liberal. The unanimity requirement has to a large extent prevented the introduction of pan-European interventionist measures. The Commission's role in this context remains somewhat ambiguous. On the one hand, it initiates policy measures that are primarily oriented to the establishment of the Single market by strengthening the realm of the four freedoms and competition policy. On the other hand, the Commission produces a number of sectorial industrial studies with recom-

\footnotetext{
${ }^{15}$ Lawton, Th. C. (1999) European Industrial Policy and Competitiveness. Concepts and Instruments, London: MacMillan Press, p. 264.

${ }^{16}$ Darmer, M. and Kuyper, L. (eds) (2000) Industry and the European Union, Cheltenham: Edward Elgar, p. 377.
} 
mendations for policy-makers that, in a more 'favourable' institutional environment could evolve into pan-European interventionist policies (Darmer, 2000) ${ }^{17}$. Besides, some examples of the EC industrial competitiveness policy indicate toward the communitarisation of protectionist elements. The examples could be controversial merger regulations, some aspects of trade policy or the EC technology policy, 'Europeanised' by French lobby groups.

It would be wrong to assume that the interventionist element was in the past alien to the EU industrial policy. Until the 1990's, regular meetings of EU Ministers of Industry and Economy focused mainly on (protectionist) collective actions in 'priority' industrial sectors, such as aeronautics, data processing, mechanical or electrical engineering, shipbuilding, textile and paper industries. However, vertical measures did not prevent European industries from further losing a competitive edge in global markets and were continuously replaced by horizontal policy mechanisms. The developments in the EU over the last decade reflect the general paradigm shift from the sectorial 'industrial policy' to the horizontal 'industrial competitiveness policy' or 'enterprise policy' taking place in most OECD economies. It is also illustrated by the latest restructuring of the European Commission and the literal replacement of the Industrial policy DG with the Enterprise DG.

Therefore, now the EU industrial policy is predominantly influenced by a liberal Single market thinking, which is reinforced by institutional factors, such as a qualified majority voting. The European competitiveness strategy, adopted in Lisbon in 1999, sets the guidelines for the current EU industrial competitiveness policy. It formulates the strategic objective for the EU "by 2010 to become the most dynamic and competitive knowledge-based economy in the world". The scope of horizontal areas covered by the strategy is wide: (1) creation of the information society, (2) creation of the Europe-wide area for research and innovation, (3) improvement of business environment (SME's), (4) completion and increased effectiveness of the Single market, (5) further integration and increased effectiveness of financial markets, (6) co-ordination of macroeconomic policies.

The Lisbon strategy objectives are implemented through the Multi-annual enterprise programme for 2001-2005, based on mainly two types of measures: horizontal financial (e.g. financial support to innovative SME's) and informational-infrastructural (information centres, benchmarking, best practice, etc.).

\section{Industrial policy as the 'management of paradoxes'}

Various authors differ in the interpretation of complex policies influencing the industrial competitiveness in the EU. Some of them (e.g. Pitelis, 1994 ${ }^{18}$ ) hold that "during the last decade the EU industrial policy was a set of ad hoc created and not necessarily compatible policies". Such inconsistencies are, for example, illustra-

\footnotetext{
${ }^{17}$ Darmer M. "EU Industrial policy in an enlarged and changing European Union", in Darmer M. And Kuyper L. (eds) "Industry and the European Union", Cheltenham: Edward Elgar, 2000, p. 377.

${ }^{18}$ Pitelis Ch., (1994) "Industrial Strategy: For Britain, in Europe and the World", Journal of Economic Studies 21 (5), pp. 3-92.
} 
ted by the EU's controversial approach to the firm size and its relationship to competitiveness. On the other hand, other authors $\left(\mathrm{Gual}, 1995^{19}\right.$, Darmer, $\left.2000^{20}\right)$ indicate certain conflicting areas and treat them as a natural fact of the Community life.

It would be difficult to disagree with the arguments calling for transparency and consistency of policy measures. However, the existing controversies about policy directions need not to be overdramatised. In a way, the very existence of these controversies is the raison d'etre of the industrial competitiveness policy in a broad sense (as opposed to the narrow sectorial sense of the traditional industrial policy), whether national or European. In our view, some degree of policy conflicts is inevitable in a complex compromise-seeking system such as the EU.

The EU (and national) industrial competitiveness policy can be quite accurately defined as "management of paradoxes". In practical terms, it means the necessity to ensure a fair competition in the internal market as well as the competitiveness of European firms in the global market. On the one hand, it is important to promote employment through small and medium enterprises, while on the other hand, not to disadvantage the growth of firms. On the one hand, it is necessary to promote the technological change inside the Community, while ensuring its social absorption. On the other hand, the promotion of the establishment of geographically condensed industrial clusters with high levels of productivity or innovation is desirable, but only being mindful of regional disparities or concentrated environmental pollution. Finally, the right balance between the measures of the external competitiveness of European economies must be found with those concerning their internal structural cohesion.

The solution of such dilemmas and paradoxes is an inseparable part of the strategic planning process. It is not surprising that the principles of strategic planning are probably most successfully introduced in the countries dominated by the integral-holistic thinking, such as East Asian countries, and, to some extent, Germany (Isaak, 1995) ${ }^{21}$. The economic systems of these countries can be described by the cohesive state-enterprise and worker-employee relationships, by their emphasis on the systemic welfare of stakeholders rather than on that of individual shareholders. The financial environment in these countries favours a long-term investment. In Japan this happens through a high savings rate, in Germany through a developed banking sector. According to Hampden-Turner and Trompenaars $(2001)^{22}$, the creation of wealth is largely determined by the capacity to successfully manage dilemmas (paradoxes), i.e. to effectively balance the extremes and accordingly manage complex processes.

\footnotetext{
${ }^{19}$ Gual J. (1995) “Three Common Policies: an Economic Analysis”, in Buigues, P., Jacquemin, A., and Sapir, A. (eds), European Policies on Competition, Trade and Industry: Conflict and complementarities, Vermont: Edward Elgar.

${ }^{20}$ Darmer, M. (1998) "A Definition of EU Industrial Policy", in Storper, M., Thomadakis, S.B., and Tsipouri, L.J. (eds) Latecomers in the Global Economy, London: Routledge, pp. 3-24.

${ }^{21}$ Isaak, R. (1997) "Making "Economic Miracles": Explaining Extraordinary National Economic Achievement", The American Economist, 41 (Spring), pp. 59-70.

${ }_{22}$ Hampden-Turner, Ch., Trompenaars, F. (2001) Building Cross-Cultural Competence, Wiley.
} 
It is natural that the opinions of researchers and different EU member states on the substance of industrial strategy are rather split. This is so mainly due to the fact that different countries seek to resolve different dilemmas, predetermined by their specific situation, the stage of economic development and the nature of their economic systems. Countries and organisations also tend to rely on their own historically successful practices, which still show a considerable degree of divergence.

It is therefore very likely that the competitiveness dilemmas resolved on the EU level provide a background, a supplement, but do not coincide with the national competitiveness dilemmas. This observation becomes of a particular relevance in the context of the forthcoming enlargement, claimed by many as unprecedented both by its substance and scope. We must ask ourselves whether the current EU industrial policies oriented to resolve the deindustrialisation, social welfare and 'triadic' competitiveness problems of the developed EU member states meet the economic restructuring challenges of the future members from Central and Baltic Europe. ${ }^{23}$ The scope of the strategic choices available to Lithuania (and to other future member states) and the capacities for their implementation should be analysed too. It is difficult to answer these questions without a prior consideration of the evolution of the strategic dimension in the context of the country's economic transformation.

\section{The EU impact on the path of economic transformation}

The unprecedented nature of the forthcoming enlargement is to some extent reflected by an unprecedented European Commission's influence on the economic policies of the candidate countries, going far beyond the usual framework of the acquis. The Commission exerted its influence as the guardian of the economic membership criteria adopted by the EU member states in the Copenhagen Summit in 1993. The economic membership criteria assess the readiness of the candidates to ensure the functioning of the market economy and the ability to withstand the competitive pressures of the EU internal market.

The dividing line between the functioning market economy and the ability to withstand competitive pressure criteria has always been thin. To some extent, the first criterion has to do primarily with the earlier mentioned macro-level policies, while the second targets micro-level policy issues. The market economy criterion is first of all associated with the establishment of market institutions and the implementation of the basic principles of market economy through (1) the creation of a legal system ensuring private ownership rights, free entry and exit from the market, (2) liberalisation of prices and trade, and (3) macroeconomic stabilization. The competitiveness criterion takes into account such variables as (1) functioning free market economy and macroeconomic stability, (2) human, physical and financial infrastructure, and prospectives for its development, (3) impact of government policies on competitiveness, (4) orientation of trade flows to the EU and (5) private capital share in GDP.

\footnotetext{
${ }_{23}$ 'Triadic' competitiveness refers to the EU competitiveness policy vis-a-vis the rest of the world (and especially Japan and the USA).
} 
It is evident that functioning market economy is considered as one of the variables in the operationalised concept of economic competitiveness. The nature of the EU impact on the economic transformation of candidate countries is very well reflected in the statement that the functioning market economy criterion should be satisfied before the competitiveness criterion. ${ }^{24}$ This requirement in principle supports the strategy of the market-based economic transformation. Thus, from the Commission's perspective, competitiveness has always been the derivative of two factors: functioning market economy and, to a lesser extent, the level of legal approximation. There is, however, no hard empirical evidence to support the assumption that any of the two could somehow lead to an automatic structural adjustment and supply-side adaptation in the transition economies.

Although the Commission in principle recognises the conceptual difference between the functioning market economy and competitiveness criteria, its actual position has always favoured the market-driven restructuring over the structural intervention by national governments. For example, the list of short-term priorities in the Accession Partnership for Lithuania of 1999 included fiscal consolidation and promotion of enterprise competitiveness, completion of a large-scale privatisation and the restructuring of the banking sector. ${ }^{25}$ The later empirical evidence showed that, in the aftermath of the Russian crisis, major attention was paid by the Commission to the macroeconomic stabilisation, which was actually achieved through an increased fiscal discipline (which, inter alia, resulted in the diminished funds for the competitiveness programmes). The restructuring of the banking sector was in fact synonymous to the privatisation of the two remaining state-owned banks. Another example could be the Law on Enterprise Restructuring, which was passed in early 2001 as a package-law with the new Law on Enterprise Bankruptcy. It was for a while scrutinised with suspicion in the Commission. Only after the Commission was confident that the law was passed to be a genuine instrument for the dialogue between the enterprises in trouble and their creditors and not for sustaining economically non-viable firms, it was included among the priorities into the Accession Partnership of 2001.

The main factors that influenced the Commission's changed perception of Lithuania's competitiveness perspectives were, in fact, the country's ability to stabilise its macroeconomic situation after the Russian crisis, its progress in privatisation (not so much in restructuring), adoption of the new version of the Law on Bankruptcy (not so much the accompanying Law on Restructuring), and partially - the adoption of a medium-term industrial development policy paper (without a strong implementation track record).

To conclude, despite its attempts for a systemic evaluation of the candidate countries, the Commission could not avoid a certain linearity in its thinking and preference for some of the assessment criteria. This assumption, however, does not imply that, from the EU's perspective, such preference was false or not well based. In our opinion, the emphasis placed by the Commission on the market-driven restructuring processes was determined by the following four factors. The Commission was acting first and foremost in order to ensure the proper functioning of the enlarged

\footnotetext{
${ }^{24}$ For example, candidate countries were invited to begin negotiations with the EU on entry terms after satisfying the first, while not necessarily fully meeting the second.

${ }^{25}$ Accession Partnerships were individualised sets of EU priorities for candidate countries.
} 
Single market. The external push for fundamental system changes in the economies of the candidate countries in their transition from the centrally planned to the market economy was needed even after most immediate measures of stabilisation in most cases successful to address macroeconomic problems (e.g. hyperinflation) at the outset of the transition were taken. The central planning system was discredited in the candidate countries, while the Commission did not trust the candidate countries' administrative capacity to effectively manage the structural change. And last, in the absence of universal progress assessment methodologies and hard acquis in the field of competitiveness policy, a priority was given to the related but more objectively identifiable factors (in this case, to a well-defined Single market acquis or standard provisions of the IMF stabilisation package).

One should make an important observation that some of the EU priorities, such as, for example, privatisation and restructuring of companies, fiscal consolidation, adoption of bankruptcy legislation, promotion of SME's or pension reforms, have no clear link with the acquis.

Meanwhile, the empirical evidence shows that Lithuania and other candidate countries have achieved more progress in the areas with well-defined acquis, both due to a better clarity of the expected actions and to more determinate Commission's evaluations ('transposed-not transposed'). For example, industrial policy and financial control (both fields formally falling outside the acquis) were the only areas, where Lithuania's progress was evaluated as 'limited' by the Commission in its 2001 Regular Report. Despite the adopted medium-term industrial policy paper, in line with the basic principles of the EU industrial policy, the further field of action remained very wide and hardly led to a more systematic use of budgetary mechanisms.

However, one should not regard the EU impact only as the reinforcement of neoliberal principles of the economic transformation or Single market thinking. The European Commission has, on the other hand, played a role in promoting the strategic planning dimension in Lithuania's economic policy. For example, the emergence of substantially new structural policies, such as regional and industrial policies, or the adoption of strategic documents, such as the National Development Plan, the Medium-term industrial policy paper owe a lot to the push by the European Commission. However, for the sake of objectiveness, one should not forget the Commission's motivation. The EU's pressure to adopt the National Development Plan is largely linked with the EU's objective to ensure a systematic and transparent use of its structural funds. Meanwhile, the strategic industrial policy paper takes its roots in the EU concerns about the effects of the Russian crisis on the national economy and the 'wrong' initial response by the Government of Lithuania through the measures infringing the competition (or more precisely - state aid) acquis.

Therefore, without denying the constructive role played by the European Commission, one should come back to the earlier formulated statement that responses to the issues or dilemmas on the EU-level may only supplement, but not substitute national-level solutions. The closer the enlargement date, the more the Commission's impact will be limited to the areas of direct concern to the Community (e.g. the EU budget or Single market acquis). It will repeatedly become obvious that the EU can be treated only as a framework for strategic choices. There is an element of paradox in the fact that with the achievement of one 'strategic' goal (i.e. the EU membership), the scope for further 'strategic' choices actually increases. 
We will further analyse the substance of the Lithuanian industrial policy in relation with the principles of the EU industrial policy. We will look at some of the best practices and, in the light of the earlier discussed strategic options, will try to assess the conditions for the effective implementation of industrial policy in Lithuania as a future member of the EU.

\section{Industrial policy in Lithuania - evolution or revolution?}

In Lithuania, just like in other centrally planned economies, until the 1990's the industrial policy of the state was oriented to the concentration of economic resources and their centralised allocation. Industrial production was based on large state-owned enterprises, functioning as part of the industrial-military complex and focusing primarily on the economies of scale. Economic resources were mainly concentrated in the manufacturing sector at the expense of services and consumer products. Such artificial industrial structure had little to do with comparative advantages that would otherwise have resulted from the free market environment. The monopolised production and the absence of supply-demand mechanisms caused ineffective and inefficient use of the capital, labour, energy and natural resources. Moreover, they eliminated any incentives the market-based innovative activities. All technological innovations were focused on increasing the economies of scale. According to Keller (1990), in a long-term perspective centrally planned economies lost their competitive edge in both high and low value-added industrial sectors and products and only partially preserved it in sectors with high concentration requirements.

However, one should also remember that in the 1960's and 1970's even the advanced Western market economies led interventionist industrial policies with an emphasis on the economies of scale as a source of competitive advantage. As it may paradoxically seem from today's perspective, industrial policies of central planning systems were then considered as a serious economic threat to the international competition. Of course, this is not a post-mortem tribute to the failed practices of central planning. This is only to illustrate that the differences in paradigm shifts, which were later occurring in the opposing economic systems (however, at different times and for different reasons) are not as fundamental and incomparable as they seem to be at first sight.

Thus, it would be misleading to assume that the current Lithuanian industrial policy was formed in a vacuum filled only with neoliberal transformation principles. In our research, we have reviewed a long list of documents implying the strategic dimension adopted by national legislators since 1990 . One of the main observations is the importance of the national security dimension on the 'strategic' thinking, at least at the initial stage of the transformation. The definitions of economic categories, such as 'strategic goods', 'strategic stock', 'strategic object', partially 'strategic investor' in national legal acts are directly associated with national security issues. Among the early national 'strategic' documents one could mention the Programme for establishing the import control and export control system of the strategic goods and technologies, National energy strategy, Strategy for search and extraction of oil, or the Law on securing the national strategic interests as regards oil provision in the emergency situations.

Thus, the first 'strategic' documents were primarily concerned with the issues 
of national security rather than sustainable economic competitiveness. At risk of too wide a generalisation, one could conclude that national security was the main factor in determining the 'strategic' aspect of enterprises. The strategic importance of a company was far less shaped by the traditional (at least in some Western economies) socialeconomic factors, such as state support to the economic "national champions" or enterprises/sectors contributing to a significant share of employment in the region. The approach also depended on the political preferences of the ruling parties. For example, from the conservative wing of the Parliament, the Baltics' largest oil refinery AB Mažeikiu nafta (Mažeikiai Oil) was regarded as a geopolitical "national champion", while from the social-democratic side, it was rather an economic-social "champion". A similar treatment can be observed in the cases of other large state-owned enterprises, like AB Lietuvos dujos (Lithuanian Gas) or Ignalinos AE (Ignalina Nuclear Power Plant). What matters, however, for our observations is that none of the approaches has so far led to the economic performance deserving the champion's name.

At this stage, it is worth repeating that the current Lithuanian industrial competitiveness policy is not emerging in a vacuum but as a result of evolutionary changes. Both the Russian crisis and the controversial privatisation process of the strategic enterprises have shown the ineffectiveness of the old policies and stimulated policy changes.

Thus, on the one hand, the conceptual changes taking place in Lithuania and other EU candidate countries to some extent replicate the general trends of EU and OECD countries. They are reflected by the acceptance of common principles of global and regional integration and knowledge economy, and characterised by a gradual transition from the traditional vertical industrial policies to horizontal measures for the industrial competitiveness. On the other hand, due to the earlier discussed specifics of the transition from the centrally planned to the market economy, the change of the industrial policy substance is so big that we can speak about the emergence of a qualitatively new policy area.

The substance of the Lithuanian industrial competitiveness policy is officially defined in the country's medium-term industrial development policy and strategy for its implementation adopted in July 2000. This document formalises a new approach to industrial policy. It provides a general SWOT analysis of the Lithuanian industry, taking into account such external factors as globalisation, knowledge society, technological changes, future membership in the EU. It formulates the strategic objective "to achieve that, by 2015, the companies carrying out their activities in Lithuania are internationally competitive, and the industrial and business structure, as well as its share in GDP be comparable with that in the developed countries". The policy principles are in general compliant with the contemporary industrial policy principles formulated by the EU or the OECD. Though the analysis singles out industrial sectors (mainly lower than medium added value) with current comparative advantage, it emphasises the need for an equal treatment of sectors and enterprises.

The policy paper explicitly states that competitiveness is a responsibility primarily resting with an enterprise rather than with the state. The state can contribute only through the creation of a favourable legal, macroeconomic business environment and horizontal measures, such as support to SME's and innovations, attraction of foreign investment, promotion of industrial co-operation, improved access to finance. To focus the policy measures, most attention is to be paid to a higher value- 
added, knowledge-intensive production. This priority is not generalised to encompass only higher value-added industries, but also higher stages of the value chains in traditional industries (e.g. production of furniture rather than raw wood in the wood sector). The international practice shows that countries still tend to build upon their existing strengths in implementing industrial development strategies. The development of clusters rarely happens in an empty place, so the strategy paper emphasises the need to carry out in-depth sectoral studies and analyse regional cluster development possibilities. The implementation of sectoral strategies would be a direct responsibility of business associations rather than government institutions.

Here, one should ask two questions. The first of them concerns the prospects that the strategy will be implemented. Nielsen (1995) notes that the different strategies of industrial restructuring adopted at different periods in the EU candidate countries (in 1991 in Estonia, in 1993 in Poland and the Czech Republic) hardly showed any record of an effective implementation, mostly because of the budgetary constraints behind the restructuring programmes. Also, neoliberal reformers often lacked the necessary political will to undertake active restructuring measures. Finally, these factors led to the substantially increased powers of the Ministry of Finance, whereas the Ministry of Economy in most countries was the main initiator of enterprise restructuring actions (though often lacking the degree of the necessary institutional restructuring itself). Very similar constraints can be observed in the case of Lithuania. One should especially emphasise the last factor. After the substantial increase in the powers of the Ministry of Finance (not without the EU's preference for the centralised co-ordination of structural funds), the Ministry of Economy remained one of the few non-reformed ministries with the main powers in sectoral issues, especially the energy policy. Thus, the experience of the last decade makes us somewhat cautious about the prospects of strategy implementation.

The second and more fundamental question concerns the substance and direction of policy implementation. As has already been mentioned, the Lithuanian medium-term industrial policy paper essentially reflects the principles of the EU industrial policy, which are, to some extent, a 'common denominator' of the industrial policies of the member states agreed in the framework of the Single market. Here we must come back and analyse whether the transposition of the EU-level policy guidelines is sufficient for the achievement of the objectives of the national competitiveness policy.

On the one hand, the EU played a positive role as it had whipped out the ineffective and potentially hazardous atavism of the old industrial policies, such as promotion of import substitutes (which were still present in the initial versions of the policy paper). The adopted policy paper has a good educational value as a collection of the right principles for government actions in the modern business environment. In principle, it fulfils its central mission - by evaluating the country's internal and external situation, to provide a conceptual basis for further industrial competitiveness programmes.

However, as Keller (1990) rightly observes, "it is more important to create a system that makes community members, boards and councils self-conscious about the impact of their decisions on a long term healthy economy than to have a fancy printed planning document, or a precisely "right" planning process". The analysis of other national cases of industrial restructuring (e.g. Ireland) tells that their success mainly depended on the capacity to objectively evaluate industry and its environment, 
and to make appropriate decisions. Both problems and solutions are specific to the country, its industrial structure, the scope of potential comparative advantages, and the stage of economic development. There can hardly be some generalised panaceas on the EU level. Solutions to industrial competitiveness dilemmas lie in the national processes of strategic planning. They are implemented not so much through centrally approved documents, but through the existing mechanisms of inter-institutional co-ordination and collective learning. Although the emergence of the policy paper is a positive phenomenon per se, it is by far an insufficient instrument for policy implementation.

\section{Industrial strategy as a system of collective learning}

Lithuania belongs to the category of "latecoming semi-industrialised countries" (LSC's) (Storper, Thomodakis, Tsipouri, 1998) ${ }^{26}$. According to these authors, such countries occupy a specific niche between the developed industrialised and developing rural economies. The 'latecomer' status means that these countries emerged as players in the international competition but "under unequal terms". They differ from the traditional developing countries as they have the basic infrastructure, educational system, rudiments of national innovation and technological transfer systems. At the same time, they differ from the developed industrial countries by insufficiently developed production structures, lack of industrial culture and modern organisational skills. Most of Central and Eastern European, South East Asian and some of Latin American countries, as well as even the less advanced EU member states fall into this category of countries.

Examples of these countries confirm several already discussed theses. The first conclusion is that traditional vertical and interventionist industrial policies no longer can serve as an appropriate instrument for modernisation of industrial structures, especially inside the EU. The most consistently successful small EU member states over the last decade, such as Ireland or Finland, followed market-oriented and open industrial policies. By the way, the ultimate shape of the Lithuanian industrial competitiveness policy paper was strongly influenced by the Irish and, especially, Finnish expert advice. Secondly, the policies of macroeconomic stabilisation proved to be insufficient and, in certain cases, even counterproductive to the industrial competitiveness.

According to Storper (1998) ${ }^{27}$, the main instrument enabling the catch-up of the 'latecoming' economies is the creation of collective learning processes or the learning economy. It is in these 'soft' aspects that the latecomers most markedly differ from the developed Western economies. In this context, it is also worth mentioning that some of the dominating Western (in fact, American) competitiveness methodologies, e.g. the influential Porter's 'diamond model', show little consideration to the soft aspects of competitiveness, such as organisational culture and the learning process (O'Shaughnessy, 1997) ${ }^{28}$. Their traditional focus of analysis is often subject to

\footnotetext{
${ }^{26}$ Storper, M., Thomadakis, S. B., and Tsipouri, L. J. (eds) (1998) Latecomers in the Global Economy, London: Routledge.

${ }^{27}$ Storper, M. (1998) "Industrial Policy for Latecomers. Products, Conventions, and Learning", in Storper, M., Thomadakis, S.B., and Tsipouri, L.J. (eds) Latecomers in the Global Economy, London: Routledge, p. 334.

${ }^{28}$ O'Shaughnessy, N. (1997) "The Idea of Competitive Advantage and the Ideas of Michael Porter", Strategic Change, 6, pp. 73-83.
} 
criticism for being limited to the developed world's leading economies and, thus, for considering only 'success factors' rather than a wider and more complex picture. Besides, there is some inherent caution about industrial policy suggestions among the American methodologists, like Porter or Drucker, although this should be a logical evolution of many of their arguments (O'Shaughnessy, 1997). So, although often very useful tools in policy-making (including the case of the Lithuanian policy paper), the models may not provide universal explanations and guidelines, but should be adjusted to local processes.

The learning economy is defined as "the organisation of firms that facilitates the effective responses to technological change through the accumulation of knowhow, continuous adaptation to new knowledge, and the pursuit of new, higher quality, more effective production" (Storper et al., 1998). The underlying rationale of the contemporary industrial strategy is not to have a centrally formulated and formally adopted strategy document with a detailed course of action, but an adequate coordination of micro and macro-level policies through the established social conventions and informal rules in order to ensure the process of collective learning.

For example, by the mid-1980's, the efforts of the Irish government to attract the export-oriented foreign direct investment helped reduce the trade deficit and balance payment problems, but it did not automatically solve the problems of national competitiveness or lead to an increased employment. On the contrary, unemployment problems grew even worse as local producers were pushed away from their markets. The underlying problem was that foreign investors were hardly integrated into the local economy. Their activities in Ireland were oriented to producing cheap labour-intensive production, based on imported raw materials and with the ultimate expatriation of profits. The MNC's needed to be integrated into the national economy to foster the further growth of competitiveness and employment.

First of all, the government started off by compensating the drawbacks of local producers by providing them with financial support to marketing activities (e.g. strengthening brand-names), implementation of new technologies, management and export training. To increase the effective use of budgetary funds, the support became more focused on 'prospective' firms and sectors so that to build upon their existing strengths. Beginning with 1984, the Industrial Development Agency experts were working with the identified companies to help co-draft the development strategies. Another programme was oriented to support potential local suppliers to foreign enterprises. The focus of the support was redirected to 'soft' areas such as export skill development, technology acquisition grants, subsidies to technological audit, etc. The financial support to technological processes increased dramatically.

Secondly, foreign investors were offered fiscal incentives to establish co-operative relations with local producers. It was important for including the latter into the value chain and knowledge networks, and for retaining more value, both in terms of money and knowledge, in the country. At the same time, incentive schemes were created to attract the higher value-added functions of MNC's (esp. marketing and $\mathrm{R} \& \mathrm{D})$. According to O'Malley $(1998)^{29}$, one of the important success factors was the

${ }^{29}$ O'Mailley, E. (1998) "Industrial Policy in Ireland and the Problem of Late Development", in Storper, M., Thomadakis, S. B., and Tsipouri, L. J. (eds) Latecomers in the Global Economy, London: Routledge, pp. 254-274. 
IDA's flexibility in negotiations on the incentive package based on the prospects of new working places, links with local suppliers, the nature of functions being transferred to Ireland. Although foreign investment was further promoted, these measures contributed to structural changes that resulted in the learning effect of local firms and the constantly rising level of employment.

In the case of Lithuania, the adopted industrial development policy is capable of ensuring a certain degree of collective learning in a short-term perspective by presenting economic and institutional actors with the main principles of competitiveness, probably even by inspiring a public debate. For example, due to this document and surrounding public discussions, the concept of 'cluster' has been entrenched in the vocabularies and, to some extent, actions of institutions and business associations.

However, for a long-term effect to take place, rules and procedures of collective learning must be created. This implies not the creation of a single administrative body more fit for realising the traditional "top-bottom" approach, but the set-up of co-ordination and communication mechanisms among the institutions implementing industrial policy. Just as Bianchi $(1998)^{30}$ puts it, "a set of conditions must be created which, however, must be grasped from below, in a sort of attempt to guide collective action through the stimulus provided by an advanced group of explorers, whose behaviour will later be taken as the standard for any future action". Storper (1998) suggests to get rid of the age-old state-market dilemma in industrial policymaking, but to identify the actors best capable of ensuring the co-operation (e.g. IDA in Ireland, MITI in Japan, etc.), to agree on the incentive systems, to structure the government-business dialogue. It is possible to conclude that none of the Lithuanian institutions is so far ready for undertaking this important role. Neither the Lithuanian Development Agency with its probably closest access to the business world, nor the Ministry of Economy as the main industrial policy-maker, have sufficient political power, financial resources and administrative capacity to effectively rely on the Irish or Japanese examples.

On the other hand, there is a range of important measures that do not require a substantial financial investment, but may contribute to an improved dialogue and collective learning. One of them is benchmarking-a systemic self-assessment in the context of other countries and sectors, comparison of performances and action plans for the catch-up. Nevertheless, to be implemented such actions must be backed up by some political will and public/private investment. The role that benchmarking plays on the organisational learning is widely recognised. Unfortunately, this practice is still in a very premature phase of development in the Lithuanian public administration. No national institution is responsible for a systemic analysis and spread of the good policy practices.

Although increasingly spreading industrial strategies lead to a somewhat increasing communication, they still hardly provide any further mechanisms enabling collective learning. However, there are, even if limited, positive examples. For exam-

\footnotetext{
${ }^{30}$ Bianchi, P. (1998) Industrial Policies and Economic Integration: Learning from European Experiences, London: Routledge, p. 228.
} 
ple, the National long-term development strategy, adopted in the Parliament in November 2002, seeks to provide more organisation to the strategic planning process in Lithuania's public administration. The methodology for strategic planning, as adopted on 6 June 2002, sets four hierarchical levels to the strategic documents: (1) National long-term development strategy (the main point of reference), (2) Longterm economic development strategy, (3) National development plan, and (4) Institutional strategic activity plans. Such classification should be capable of ensuring a better co-ordination of the strategic planning process among institutions and their policies.

To conclude, the actual effects of the recent 'boom' of strategic planning in the national public administration are still too early to be objectively evaluated. Although the experiences of the past should make us sceptical, one should also take into consideration the dramatically changing country's internal and external environment. The whole set of old factors influencing strategic thinking is disappearing, while new factors are emerging. With the process of the economic transformation close to completion, the impact of international financial institutions, such as the IMF or the World Bank, on the national economic policy will be decreasing. The forthcoming completion of the privatisation process should appease the discussions on 'strategic' enterprises. The approaching membership date in the EU, on the one hand, puts an end to the EU requirements falling outside the acquis, whereas on the other hand, it sets clear rules for national structural intervention.

It is somewhat paradoxical that, in a way, the attainment of the 'strategic' objective of the EU membership leads to an even wider scope of 'strategic' choices, though in a rather strictly defined framework. The increasing complexity of the country's policy-making environment sets new tasks for strategic planning. How to ensure that the competitive Single market environment contributes to the growth rather than the detriment of local firms? Which of the niches in the Single market acquis can be used in order to create a favourable business environment responsive to the country's development needs (e.g. as regards the use of the acquis-compliant incentive package)? How to ensure the systemic use of the EU structural funds for the increasing national competitiveness? How to find the right balance between the fiscally restrictive macroeconomic obligations for the EMU membership (i.e. convergence criteria) with the structural policy objectives? Finally, how to identify the critical interests of national competitiveness and represent them effectively when adopting the new EU acquis?

The quality of the answers to these questions and the effectiveness of strategic planning will be determined both by the political will to identify and empower the actors capable of ensuring co-ordination and collective learning as well as by the actual administrative capacity for their implementation. 